\title{
(D)
}

\section{Percursos da Formação Inicial em Pedagogia na legislação brasileira: desafios para a docência na Educação Infantil}

\section{Routes of Initial Learning in Pedagogy in the Brazilian Legislation: Challenges forTeaching in Early Childhood Education}

Itinerarios de la Formación Inicial en Pedagogía en la legislación brasileña: desafíos para la docencia en la Educación Infantil

\author{
Valdete Côco* iD orcid.org/0000-0002-5027-1306 \\ Maria Nilceia de Andrade-Vieira** (iD orcid.org/0000-0001-7723-6490 \\ Karina de Fátima-Giesen*** (iD orcid.org/0000-0002-2085-210X \\ Dilza Côco*** iD orcid.org/0000-0001-8371-8517
}

Para citar este artículo

Côco, V., Andrade-Vieira, M., Fátima-Giesen, K. e Côco, D. (2021). Percursos da Formação Inicial em Pedagogia na legislação brasileira: desafios para a docência na Educação Infantil. Revista Colombiana de Educación, 1(83), 1 18. https://doi.org/10.17227/rce.num83-10811.

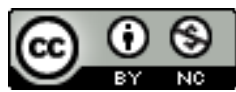

\footnotetext{
*Doutora em Educação pela Universidade Federal Fluminense; Professora vinculada ao Departamento de Linguagens, Cultura e Educação e ao Programa de Pós-graduação em Educação do Centro de Educação da Universidade Federal do Espírito Santo, Brasil. Correo: valdetecoco@hotmail.com

** Doutoranda em Educação pelo Programa de Pós-graduação em Educação do Centro de Educação da Universidade Federal do Espírito Santo. Professora da Faculdade Estácio de Vila Velha, Brasil. Correo: nilceia_vilavelha@hotmail.com 


\section{Resumo}

\author{
Palavras-chave: formação \\ de professores; legislação \\ educacional; história \\ educacional; docência; \\ educação infantil
}

Numa perspectiva histórica da Pedagogia e em vinculação com o direito à educação, este artigo analisa as premissas estabelecidas para a Formação Inicial de professores para a docência, na Educação Infantil no contexto das transformações que marcam as atuais políticas públicas educacionais brasileiras. Baseado em referenciais teóricometodológicos de Mikhail Bakhtin, este texto decorre de uma pesquisa de abordagem qualitativa e de cunho bibliográfico, desenvolvida por meio de análise documental da legislação educacional brasileira, com destaque para a vigência da Lei 13.005/2014, que institui o Plano Nacional de Educação, da Resolução 01/2006, que estabelece as Diretrizes Curriculares Nacionais para 0 curso de graduação em Pedagogia, e da Resolução 02/2015, que define as Diretrizes Curriculares Nacionais para a Formação Inicial em nível superior assim como para a formação continuada. Considerando a pertinência na produção de políticas públicas, os documentos reúnem concepções que se vinculam a diferentes contextos sóciohistóricos, evidenciando diversas (por vezes, divergentes) perspectivas e interpretações, dirigidas aos processos formativos dos docentes e ao trabalho educativo com as crianças. As análises efetuadas indicam problematizações referentes à organização curricular, à dinâmica das ações e às interfaces com o campo de trabalho, por isso assinalam que os ordenamentos legais se efetivam em meio a disputas e tensões. Ainda assim, elas atestam a formação em nível superior como uma conquista e enfatizam a relevância do cumprimento das metas e estratégias do Plano Nacional de Educação no horizonte da defesa do direito das crianças pequenas à educação de qualidade socialmente referenciada.

\section{Abstract}

In a historical perspective of Pedagogy and in a connection with the right to education, this article analyzes the established premises for the teachers' initial training for teaching in the education of children regarding the context of the transformations that mark the current Brazilian educational public policies. Based on Mikhail Bakhtin's, in the theoreticalmethodological frameworks, it stems from a qualitative and bibliographical approach research, developed through a document analysis of the Brazilian educational legislation, with emphasis on Law 13.005/2014, which establishes the National Education Plan. Also, on the Resolution 01/2006, which establishes the National Curricular Guidelines for the course in Pedagogy, and the Resolution 02/2015, which defines the National Curricular Guidelines for the initial formation in higher education and the continuing education of teachers. Considering the relevance in the production of public policies, the documents bring together elaborated conceptions in different socio-historical contexts, and they highlight several (sometimes divergent) perspectives and interpretations directed to the educational processes of the teachers and the educational work with the children. The analyzes indicate problematizations regarding curricular organization, the dynamics of actions and interfaces with the field of work. This shows that legal systems are effective amidst in terms of disputes and tensions. Nonetheless, they point the higher education as an achievement and emphasize the relevance of knowing the goals and strategies of the National Education Plan to defend the right of young children to a socially acknowledged quality education.

\section{Resumen}

En una perspectiva histórica de la Pedagogía y en vinculación con el derecho a la educación, este artículo analiza las premisas establecidas para la formación inicial de profesores para la docencia en la educación infantil, en el contexto de las transformaciones que marcan las actuales políticas públicas educativas brasileñas. Con anclaje en referenciales teórico-metodológicos de Mikhail Bakhtin, se deriva de una investigación de abordaje cualitativo y de naturaleza bibliográfica, este texto está desarrollado por medio de un análisis documental de la estrategia educativa brasileña, con destaque para la vigencia de la Ley 13.005/2014, que instituye el Plan Nacional de Educación, así como de la Resolución 01/2006, que establece las Directrices Curriculares Nacionales para el curso de pregrado em Pedagogía, y de la Resolución 02/2015, que define las Directrices Curriculares Nacionales para la formación inicial a nivel superior y formación continuada. Em vista de la relevancia en la producción de políticas públicas, los documentos reúnen concepciones que se vinculan con diferentes contextos sociohistóricos, evidenciando diversas (a veces divergentes) perspectivas e interpretaciones, dirigidas a los procesos formativos de los docentes y al trabajo educativo con los niños. Los análisis indican problemáticas referentes a la organización curricular, a la dinámica de las acciones y a las interfaces con el campo de trabajo, señalando que los ordenamientos legales se efectúan em medio de disputas y tensiones. Sin embargo, indican la formación a nivel superior como una conquista, enfatizando la relevancia del cumplimiento de las metas y estrategias del Plan Nacional de Educación en el horizonte de la defensa del derecho de los niños pequeños a la educación de calidad socialmente referenciada. 


\section{Introdução}

Fundamentado numa perspectiva histórica da Pedagogia e integrado ao contexto das políticas públicas educacionais brasileiras, este artigo analisa as premissas estabelecidas para a Formação Inicial (FI) de professores concernentes à docência na Educação Infantil (EI), no cenário das transformações que marcam as normatizações educacionais. Em vinculação com o direito à educação, o presente texto é parte de uma pesquisa ${ }^{1}$ mais ampla que acompanha o curso de Pedagogia no Brasil a partir de ordenamentos legais, da produção acadêmica em torno da temática (Côco, Vieira e Giesen, 2018; 2019) e, sobretudo, em interlocução com estudantes de uma universidade pública da região sudeste do país.

Com base em concepções bakhtinianas, valorizamos o contato com enunciados que nos antecedem, pois acreditamos que somos simultaneamente ouvintes e falantes, e que "cada enunciado é um elo na corrente complexamente organizada de outros enunciados" (Bakhtin, 2011, p. 272). Buscando participar dessa teia dialógica associada à tematização da formação de professores, este artigo também interage com premissas sobre a docência na EI (Kramer, 1995; Côco, 2013; Buss-Simão e Rocha, 2018), sobre a trajetória do curso de Pedagogia (Silva, 2003; Scheibe, 2007 e 2011; Saviani, 2009) e sobre os ordenamentos legais (Scheibe, 2011; Durli, 2007; Dourado, 2015). No reconhecimento de avanços alcançados nas últimas décadas, assim como da imposição de retrocessos a essas - ainda que incipientes conquistas, o diálogo com diferentes estudos e pesquisas nos possibilita demarcar posicionamentos e compreender que este é "o momento de reafirmar a importância da Resolução 02/2015 como sendo um marco histórico para a organização, gestão e institucionalização da formação de professores no Brasil" (Associação Nacional de PósGraduação e Pesquisa em Educação, ANPEd, 2018). Sendo assim, nossa inserção neste debate está articulada à defesa da qualificação da FI de professores, implicada com o reconhecimento da emergência de distintas compreensões para as vivências associadas ao curso de Pedagogia (Côco, Galdino e Vieira, 2017).

No cenário brasileiro, a formação de professores tem ganhado centralidade no debate educacional, com movimentos dialógicos que convidam à mobilizações e questionamentos. Nesse quadro, destacamos assertivas afirmadas pelos movimentos da sociedade civil organizada, dentre eles, a Associação Nacional pela Formação dos Profissionais da Educação (ANFOPE), que no Art. $1^{0}$ de seu Estatuto de 2009 indica que é preciso "fazer avançar o conhecimento no campo da formação e da valorização dos profissionais da educação, por meio da mobilização de pessoas, de entidades e de instituições dedicadas a essa finalidade" (ANFOPE, 2011 , p. 7). Nesse contexto, tematizar a formação docente é importante para a compreensão e melhoria do trabalho com as crianças de zero a cinco anos, sobretudo no reconhecimento delas como sujeitos de direitos que produzem cultura nas vivências com outras crianças e com adultos, como preconiza a Resolução 05/2009 que instituiu as Diretrizes Curriculares Nacionais para a Educação Infantil (Brasil, 2009).

A pesquisa coletiva do Grupo de Pesquisa Formação e Atuação de Educadores (Grufae), intitulada "A Educação Infantil na Formação Inicial em Pedagogia: enunciados discentes", iniciada em 2018, vem buscando compreender os sentidos enunciados por estudantes de um curso de Pedagogia sobre a docência na El, em interlocução com a trajetória desta etapa na formação superior e com as produções acadêmicas do campo. 
Para sistematizar a abordagem desse tema, dividimos o desenvolvimento deste estudo em quatro partes principais. Após esta introdução, compartilhamos os pressupostos teóricometodológicos caracterizados por uma breve abordagem conceitual, pela apresentação do posicionamento da formação docente para a EI na dialogia com outros autores e pelo detalhamento da análise documental. Em seguida, abordamos a trajetória do curso de Pedagogia no Brasil, realçando marcos de sua constituição até os dias atuais. Pontuamos, então, fatos e estudos acerca da FI, de modo a demarcar a temática a partir das normativas para a FI no curso de Pedagogia (Brasil, 2006) e para os processos de FI e continuada de professores (Brasil, 2015), em vinculação com metas do Plano Nacional de Educação (PNE) (Brasil, 2014) e reformulações apontadas para a formação (Brasil, 2019b). Por fim, tecemos nossas considerações finais com um convite às contrapalavras ${ }^{2}$, destacando a necessária mobilização para que a Resolução 02/2015 seja retomada e possa ganhar materialidade no contexto brasileiro.

\section{Pressupostos teórico-metodológicos}

Diante do propósito deste texto, apresentamos a EI como direito das crianças e de suas famílias (Brasil, 1988) e ressaltamos o percurso de desafios e conquistas com seu pertencimento à educação básica (Brasil, 1996), assim como as lutas pelo reconhecimento de sua especificidade (Brasil, 2009). Integrada à educação básica, a EI abarca a creche com atendimento às crianças de 0 a 3 anos, e a pré-escola com crianças de 4 a 5 anos. Deve-se ter em vista que a educação obrigatória, no Brasil, engloba a faixa etária de 4 a 17 anos, cobrindo em parte a EI. Com isso, para a esfera da creche reforça-se a compreensão do direito à educação (tal como nas outras etapas e níveis de ensino), a despeito do requisito de obrigatoriedade. Assim, a atuação docente na EI integra o debate sobre a formação de professores, pois demanda processos formativos que reconheçam as particularidades da docência com crianças pequenas.

Para debater os processos formativos requeridos pela EI, compreendemos que, "por formação inicial entendem-se os processos institucionais de formação de uma profissão que geram a licença para o seu exercício e o seu reconhecimento legal e público" (Cunha, 2013, p. 612). Nessa perspectiva, para atuação na EI, a legislação brasileira prevê a FI no curso superior em Pedagogia, admitida a formação em nível médio na modalidade Normal (Brasil, 1996). Essa FI, requerida para entrada no campo de atuação, se associa à Formação Continuada (FC), como um direito dos profissionais. Em uma perspectiva histórica, cumpre destacar, que "a pedagogia se desenvolveu em íntima relação com a prática educativa, constituindo-se como a teoria ou ciência dessa prática sendo, em determinados contextos, identificada com o próprio modo intencional de realizar a educação" (Saviani, 2007, p. 100). Nesse sentido, a Pedagogia tem como propósito a sistematização e produção de conhecimentos, articulando os diferentes saberes produzidos socialmente. No Brasil atual, 0 curso de Pedagogia habilita para a docência (circunscrita à EI e aos anos iniciais do ensino fundamental) e para a gestão, aliada à formação para a pesquisa e para a atuação em

A partir do conceitual bakhtiniano "Compreender é opor à palavra do outro uma contrapalavra" (Bakhtin, 2006, p. 135). Na percepção de que o diálogo se estabelece entre 0 eu e o outro, nossa atitude responsiva em relação ao enunciado anteriormente proferido, por vezes discordante, constitui uma contrapalavra.

Número 83, Tercer cuatrimestre de 2021 (septiembre-diciembre) || e-ISSN: 2323-0134 || 4 
processos educativos não escolares como definem as Resoluções 01/2006 e 02/2015 (Brasil, 2006; 2015).

Situada a EI no diálogo com a formação de professores e o curso de Pedagogia, focalizamos, com ancoragem em referenciais teórico-metodológicos bakhtinianos (Bakhtin, 2011), os percursos da legislação brasileira. Evidenciamos reflexões decorrentes de análise documental da legislação educacional, com destaque para a Resolução 01/2006, que estabeleceu as Diretrizes Curriculares Nacionais para o curso de graduação em Pedagogia, para a Lei 13.005/2014, que institui o PNE, para a Resolução 02/2015, a qual define as Diretrizes Curriculares Nacionais para a Formação Inicial em nível superior e para a Formação Continuada, em interlocução com a Resolução 02/2019 que institui a Base Nacional Comum para a Formação Inicial de professores da Educação Básica. Nesse contexto, trabalhamos com Bakhtin (2013) na abordagem às normativas legais para assinalar a presença de múltiplas vozes (por vezes conflitantes) nas pautas em questão.

Considerando a pertinência da produção de políticas, buscamos também, em diálogo com Ball $(2001 ; 2009)$, demarcar os contextos em que estas se localizam nas discussões em curso no campo, com atenção aos tensionamentos de poder existentes nesses movimentos e de registro e aprovação dos "consensos" destas discussões. Nesse sentido, importa atentar para as significações que tais normatizações adquirem nos contextos práticos de sua efetivação, tendo em vista que:

A criação das políticas nacionais é, inevitavelmente, um processo de "bricolagem"; um constante processo de empréstimo e cópia de fragmentos e partes de ideias de outros contextos, de uso e melhoria das abordagens locais já tentadas e testadas, de teorias canibalizadoras, de investigação, de adoção de tendências e modas e, por vezes, de investimento em tudo aquilo que possa vir a funcionar. (Ball, 2001, p. 102)

$\mathrm{Na}$ intenção de analisar os eventos e problematizar sua construção para além da linearidade temporal, dialogamos ainda com a abordagem histórica de Bloch (2002), para ressaltar a necessidade de estabelecer relações entre passado e presente, uma vez que a ação do homem se efetiva no contexto histórico e no espaço-tempo. Nessa mesma direção, Bakhtin assevera que, nos diferentes momentos da história, a linguagem é plural. Para ele, "deve-se isso à coexistência de contradições socioideológicas entre presente e passado, entre diferentes épocas do passado, entre diversos grupos socioideológicos" (Bakhtin, 2010, p. 98). Nessa perspectiva de relações entre as temporalidades, exploramos na próxima seção um conjunto de eventos marcantes do contexto brasileiro no que se refere ao curso de Pedagogia.

\section{Trajetória do curso de Pedagogia no Brasil}

No reconhecimento de nossa constituição como sujeitos, imersos no contexto social e histórico, e em função do propósito deste texto de focalizar a FI de professores para o campo da EI, retomamos, brevemente, a trajetória do curso de Pedagogia, tendo como referência a legislação brasileira. Cientes de que os eventos não se encontram isolados, buscamos relações entre movimentos retrospectivos e prospectivos, no intuito de interpretar as conjunturas vivenciadas. Nessa interpretação, portanto, entendemos passado, presente e futuro de modo interligado, configurados numa orquestração complexa em que diferentes forças interagem e atuam nas decisões. Assim, "o passado não precisaria ter sido o que foi, o presente pode ser diferente do que é e [...], portanto, é possível mudar o futuro" (Kramer, 2000, p. 158). 
Com essa compreensão, antes da discussão sobre o curso de Pedagogia no Brasil, destacamos iniciativas precedentes à sua instauração relacionadas à formação de professores. De acordo com Saviani (2009), no período 1827 a 1890 prevaleceu no país o modelo das Escolas Normais, estabelecidas pela Lei das Escolas de Primeiras Letras. ${ }^{3}$ Entre 1890 e 1932, ocorreu a expansão dessas escolas, caracterizada pela criação da escolamodelo anexa à Escola Normal em São Paulo, que se estendeu para as principais cidades do interior do estado e se tornou referência também para outros estados do país. Avançando para um terceiro período desde 1932 até 1939, ganha força no cenário nacional a organização dos Institutos de Educação, cujos marcos são as reformas de Anísio Teixeira, no Distrito Federal, em 1932, e de Fernando de Azevedo, em São Paulo, em 1933 (Saviani, 2009).

Nesse ínterim, as discussões sobre a criação do curso de Pedagogia no Brasil se tornam mais intensas, uma vez que a partir da década de 1930, dado o contexto de alterações das concepções educacionais, emerge a defesa da universalização da educação. Essa defesa foi pautada, sobretudo, pelo Movimento dos Pioneiros da Escola Nova, uma organização de pensadores de diferentes áreas que, ancorados em ideais de educação pública, gratuita e laica, propunham um novo projeto educacional para o Brasil em oposição à Escola Tradicional.

Nesse contexto, foram criadas a Universidade de São Paulo (1934) e a Universidade do Distrito Federal (1935), tornando efetivas a organização e a implantação das licenciaturas e do curso de Pedagogia, estendidos para todo o país pelo Decreto-Lei 1.190 de 1939. Cabe assinalar que o momento histórico do regime político fundado por Getúlio Vargas (1937 1945) foi denominado Estado Novo (Durli, 2007; Scheibe e Durli, 2011).

Com a estruturação das Faculdades de Filosofia, Ciências e Letras a partir do DecretoLei 1.190 de 1939 (Brasil, 1939), tem início a formação de professores em nível superior. A partir desta legislação, a formação seguiu o esquema "3+1". Essa estrutura se caracterizava por duas finalidades, atendendo aos ditames de uma proposta universitária profissionalizante, com o propósito de formar técnicos em educação para atuar junto à estrutura burocrática dos sistemas de ensino, mediante a titulação de bacharel, alcançada após três anos de estudos e de formar para o exercício da docência no ensino secundário e particularmente no Normal, com o acréscimo de mais um ano de estudos, então denominados de Didática (Scheibe e Durli, 2011).

Saviani (2009), destaca que no final da década de 1960 e início da década de 1970, com o golpe militar de 1964, foram realizadas novas mudanças na legislação de ensino. Em decorrência, a Lei 5.692/71 (Brasil, 1971) modificou os ensinos primário e médio, alterando sua denominação respectivamente para primeiro e segundo grau. Nessa nova estrutura, extinguiram-se as Escolas Normais e em seu lugar foi instituída a habilitação específica de segundo grau para o exercício do magistério de $1^{\circ} \mathrm{grau}$.

Ainda nessas décadas, há uma série de reformas relativas ao ensino superior em 1968 e ao ensino primário e médio em 1971. Scheibe e Durli (2011), assinalam que, essas alterações foram marcadas especialmente pelo vínculo entre educação, mercado de trabalho e a modernização de hábitos de consumo. Alterações caracterizadas, segundo as autoras, pela necessidade de integração aos planos gerais de desenvolvimento e segurança

Nesse contexto, a primeira Escola Normal do Brasil foi instalada em Niterói, no Rio de Janeiro, em 1835, para a habilitação das pessoas ao magistério da instrução primária. 
nacional, defesa do Estado, repressão e controle político-ideológico da vida intelectual e artística do país.

De acordo com Scheibe e Durli (2011), o Decreto-Lei 53/1966 fixou princípios e normas de organização para as universidades federais. Esse decreto, incorporado à Lei 5.540/1968, que entrou em vigor no governo de Costa e Silva (1967-1969), e que fixava normas de organização e funcionamento do ensino superior. Essa lei definiu, no Art. 30, os especialistas que atuariam nos sistemas de ensino, desenvolvendo funções de Administração, Planejamento, Inspeção, Supervisão e Orientação.

No bojo de lutas pela redemocratização 4 do país, foi promulgada, em 1988, uma nova Constituição Federal (Brasil, 1988), denominada de Constituição Cidadã. Com este novo ordenamento, havia que se elaborar uma nova lei de diretrizes para a educação. Após ampla discussão em todo o país por diferentes entidades organizadas de educadores e da sociedade civil, ainda que não contemplasse as reivindicações pautadas pelos educadores, a Lei de Diretrizes e Bases (LDB) (Brasil, 1996) foi finalmente votada no Congresso Nacional (Scheibe e Durli, 2011).

A norma que constava do Art. 62 da LDB, no Título VI, previa como formação mínima para o exercício do magistério na EI e nos anos iniciais do ensino fundamental a formação de nível médio na modalidade Normal, atribuía aos cursos de Pedagogia o papel de formadores de profissionais de educação para funções de administração, planejamento, inspeção, supervisão e orientação educacional destinada à educação básica (Saviani, 2009). ${ }^{5}$ Conforme destaca Durli (2007), a lei não extinguiu o curso de Pedagogia. No entanto, reduziu o seu âmbito de atuação à formação de especialistas e reservou a função de formar professores para a EI e anos iniciais do ensino fundamental para o curso Normal Superior.

Entretanto, a autora assinala que o curso de Pedagogia manteve-se formando os professores para essas etapas, segundo o entendimento até então defendido pelas entidades representativas da área da educação. Tal atitude de resistência levou os cursos normais superiores, criados ao sabor da recém-aprovada legislação, à extinção gradativa. Com a aprovação da Resolução 01/2006, os cursos normais superiores foram decrescendo por ausência de finalidade. A perspectiva de Saviani mostra que:

A nova LDB promulgada em meio a grandes disputas, não correspondeu a essa expectativa. Introduzindo como alternativa aos cursos de pedagogia e licenciatura os institutos superiores de educação e as Escolas Normais Superiores, a LDB sinalizou para uma política educacional tendente a efetuar um nivelamento por baixo: os institutos superiores de educação emergem como instituições de nível superior de segunda categoria, provendo uma formação mais aligeirada, mais barata, por meio de cursos de curta duração. (2009, p. 148)

Assim, as reformulações na dinâmica do curso de Pedagogia representam embates históricos, pois evidenciam divergências de propósitos (Silva, 2003), marcados por tensionamentos que envolvem o contexto social mais amplo. Nessas discussões, nos

Nesse período organizou-se o Movimento Nacional pela Reformulação dos Cursos de Formação dos Educadores, iniciado com a criação do Comitê Nacional Pró-Formação do Educador (1980) e transformado, em 1983, na Comissão Nacional de Reformulação dos Cursos de Formação do Educador (CONARCFE), resultando, em 1990, na criação da ANFOPE.

Tal determinação foi recentemente ratificada pela Lei n 12.796 (Brasil, 2013), que, ao fazer alterações na LDB, manteve a possibilidade dessa formação como exigência mínima para o exercício do magistério nos níveis iniciais de escolarização. 
valemos dos pensamentos bakhtinianos para compreender que as muitas vozes presentes nos textos (de caráter mandatários, de propósitos orientadores, de explicitação de manifestações e outros) integram relações sociais de poder (Bakhtin, 2010). Nesse quadro se incluem as normativas selecionadas para este diálogo, que ressaltam a atualidade dessas discussões, conforme desenvolvemos a seguir.

\section{A formação inicial de professores para a educação infantil nos textos da legislação brasileira}

Avançando na síntese do histórico das normativas da formação de professores no contexto brasileiro, seguimos com o intuito de empreender, mais detidamente, uma análise documental da atual legislação educacional brasileira, com destaque para a Lei 13.005/2014, para a Resolução 01/2006 e para a Resolução 02/2015. Nesse percurso, destacamos as legislações em vigência que, conforme assinalado, estão tensionadas por ações do Conselho Nacional de Educação (CNE), que reformulou as normativas da formação de professores (Brasil, 2019c), repercutindo em questionamentos de associações científicas da área (ANPEd, 2019; ANFOPE, 2018). Essas proposições de alteração nas normativas se efetivam no contexto de ataques ao direito à educação (ANPEd, 2016), por meio da redução de investimentos em políticas sociais e da implantação de uma Base Nacional Comum Curricular (ANPEd, 2015; 2018).

Cabe destacar que, no pensamento bakhtiniano, as palavras adquirem significação quando são imersas em contextos sociais de interação verbal entre os sujeitos falantes. Assim, importa assinalar que a Resolução 01/2006 foi sistematizada no contexto das legislações já existentes e decorreu de um longo processo de discussões, permeadas por processos avaliativos e consultas públicas, como podemos inferir a partir dos pareceres CNE 05/2005 e CNE/CP 03/2006.

As análises de Durli e Bazzo (2008), destacam que, no período desde a pós-aprovação LDB até 2006, "educadores e entidades [em especial a ANFOPE] acompanharam o movimento da legislação, mobilizando-se no sentido de pressionar para que as propostas da sociedade civil, das entidades representativas da área da educação, fossem consideradas" (p. 211). Esse movimento de demarcar as lutas no campo foi fundamental para os embates travados na formulação das diretrizes nacionais para o curso de Pedagogia, uma vez que a proposta elaborada pela Comissão Bicameral designada pelo CNE (em 2005) acaba por reduzir o curso "ao pragmatismo da docência para as séries iniciais da Educação Fundamental ou para a EI e aprofunda a dicotomia entre teoria e prática" (Durli e Bazzo, 2008, p. 214).

As discussões fomentadas pelas entidades e grupos de professores permitiram alterações no projeto, por isso o conteúdo da resolução aprovada decorreu "de um processo de tensionamento entre propostas antagônicas, mas também da busca de consensos possíveis" (Durli e Bazzo, 2008, p. 216). Produto desse processo, a Resolução 01/2006 institui as Diretrizes Curriculares Nacionais para o Curso de Graduação em Pedagogia (licenciatura), definindo os princípios e as condições de ensino e de aprendizagem a serem proporcionados e avaliados pelas instituições de ensino superior aos estudantes do curso. O contexto de tal elaboração permitiu que as deliberações a respeito da FI em Pedagogia estivessem centralizadas no exercício da docência que, no primeiro parágrafo do Art. $2^{\circ}$ dessa resolução, é compreendida: 
Como ação educativa e processo pedagógico metódico e intencional, construído em relações sociais, étnico-raciais e produtivas, desenvolvendo-se na articulação entre conhecimentos científicos e culturais, valores éticos e estéticos inerentes a processos de aprendizagem, de socialização e de construção do conhecimento, no âmbito do diálogo entre diferentes visões de mundo. (Brasil, 2006)

Diferenciando-se da formação empreendida até então nas instituições de ensino superior do país, o curso de licenciatura em Pedagogia passa a ser destinado à formação de professores para exercer funções de magistério nos anos iniciais da educação básica, assim como em cursos de ensino médio (modalidade Normal) e em demais etapas educacionais em que fossem previstos conhecimentos pedagógicos, como evidenciado no Art. $4^{\circ}$ da resolução. Nesse contexto de valorização da docência, destacamos as conquistas que se vinculam à EI, visto que a resolução afirma, no inciso II do Art. 50, como aptidão esperada aos egressos do curso a compreensão, o cuidado e a educação das crianças de zero a cinco anos de idade, com vistas a contribuir para o desenvolvimento destas nas dimensões intelectuais, físicas, psicológicas e sociais, entre outras.

Ainda nos investimentos para formar professores aptos a atuarem na primeira etapa da educação básica, a resolução, em seu Art. 70, propõe a carga horária do curso, destinando no mínimo 300 horas de estágio supervisionado, a serem realizadas prioritariamente em instituições de EI e nos anos iniciais do ensino fundamental, garantindo aos licenciandos experiências de exercício da profissão, a partir de inserções supervisionadas. Em suma, as alterações propostas na Resolução 01/2006 avançam nas reivindicações de movimentos organizados de educadores, ao romper com as dualidades entre formação de docentes e de especialistas em educação, entre licenciatura e bacharelado (Scheibe, 2007).

No âmbito da legislação brasileira, destacamos também a Lei no 13.005/2014, que estabelece o PNE, apresentando 20 metas (com 254 estratégias) a serem cumpridas em até dez anos. Ao atender o previsto no Art. 214 da Constituição Federal (Brasil, 1988), tal plano objetiva articular o sistema educacional no país, respeitando o regime de colaboração, e assegurar o desenvolvimento e a manutenção do ensino nacional em seus diferentes níveis, etapas e modalidades.

Os debates a respeito de um plano de educação que atendesse as demandas nacionais intensificaram-se com a realização da Conferência Nacional de Educação, em 2010. A respeito desse processo, Dourado afirma que:

A aprovação do Plano Nacional de Educação pelo Congresso Nacional e a sanção Presidencial, sem vetos inauguraram uma nova fase para as políticas educacionais brasileiras. Além das diretrizes que são sinalizadoras de busca de maior organicidade para a educação nacional no decênio 2014/2024, o PNE apresenta a discussão sobre qualidade, avaliação, gestão, financiamento educacional e valorização dos profissionais da educação. (2015, p. 301)

Ao observarmos o Plano Nacional de Educação (PNE Brasil, 2014) aferimos que, dentre as 20 metas propostas, seis apresentam pelo menos uma estratégia com ações relativas à FI de profissionais. Entre as metas, uma versa especificamente sobre a EI e duas de suas estratégias recaem sobre a FI de profissionais para atuarem nesta etapa educacional.

A meta direcionada especificamente à FI de profissionais da educação é a meta 15, que dispõe sobre a garantia de uma política nacional de formação, em consonância com a LDB (Brasil, 1996), na busca por assegurar "que todos os professores e as professoras da educação básica possuam formação específica de nível superior, obtida em curso de licenciatura na área de conhecimento em que atuam" (Brasil, 2014, p. 12). Desse modo, a 
formação em nível superior para professores da educação básica se mostra como uma conquista, mobilizada nos tensionamentos da discussão que envolve os coletivos organizados de professores.

Ao integrar o conjunto de estratégias de outras metas $(5.6 ; 7.22 ; 7.26 ; 10.2 ; 10.8$; $10.11 ; 13.9 ; 15.4)$, a FI de profissionais da educação articula-se aos conhecimentos de novas tecnologias; à especialização para os técnicos administrativos das secretarias de educação; à oferta de programas para a formação para atuação em educação escolar no contexto de populações tradicionais, itinerantes, indígenas e quilombolas, assim como em sua expansão a partir da educação de jovens e adultos; e ao estímulo à formação para técnicos administrativos da educação superior.

Ainda neste movimento de associação a outras metas, em especial à meta 1 (que trata da universalização e da ampliação do atendimento na EI), o PNE visa a "promover a formação inicial e continuada dos (as) profissionais da educação infantil, garantindo, progressivamente, o atendimento por profissionais com formação superior" (Brasil, 2014, p. 3). No que se refere a prazos, o termo "progressivamente" nos impele a inferir que a realização dessa estratégia deverá ocorrer até o final da vigência do plano, o que requer a mobilização em defesa de sua efetivação como uma importante conquista para a EI. Embora reconhecendo que, a docência desenvolvida por trabalhadores formados ainda carece, no bojo das instituições educacionais, de fortalecimento no contexto recente do atendimento às crianças pequenas, as vozes presentes no plano contribuem para a superação do assistencialismo nesta etapa, assim como para a valorização do magistério (Côco et al., 2015).

Em atendimento à meta 15 do PNE, mais diretamente às estratégias 15.6 e 15.7, a Resolução 02/2015, decorrente das discussões iniciadas com a LDB e reforçada no PNE, inscreve-se no contexto das discussões a respeito de uma base comum nacional, que priorize as universidades como principais lócus de realização deste projeto de formação:

Por meio da efetiva articulação dessas IES [Instituições de Ensino Superior] com os entes federados, seus sistemas e redes, instituições de educação superior e instituições de educação básica, sem descurar da efetiva participação dos fóruns permanentes de formação e demais instâncias como conselhos nacional, distrital, estaduais e municipais e respectivos fóruns. (Dourado, 2015, p. 315)

Nesse sentido, a Resolução 02/2015 avança ao trazer consigo contribuições das entidades e organizações de profissionais da educação, ampliando a concepção de trabalho docente. Assim, a preparação de profissionais para o magistério (nas diferentes etapas e modalidades da educação básica), ganha destaque no nível superior "para uma atuação docente que objetive [...] garantir, com qualidade, os direitos e objetivos de aprendizagem e o seu desenvolvimento, a gestão democrática e a avaliação institucional" (Brasil, 2015, p. 3).

No capítulo III, em seu Art. $8^{\circ}$, e mais especificamente nos incisos XI a XIII, ao definir os conhecimentos dos quais os egressos de processos de FI e/ou continuada devem se apropriar, a resolução estabelece a importância do conhecimento sobre a realidade sociocultural dos estudantes e sobre os processos de ensinar e de aprender, assim como da necessidade de reflexão sobre a própria prática e da discussão e disseminação desses conhecimentos, além da compreensão crítica das normativas legais. Cabe assinalar que a apropriação desses conhecimentos, compõe os desafios de adequação dos cursos de Pedagogia a esta normativa. 
Ainda que evidencie a necessidade de formação para uma docência integrada ao contexto da educação básica e determine, nas orientações à estruturação do currículo dos cursos (capítulo v), o aumento da carga horária dedicada ao estágio supervisionado para 400 horas, a resolução não especifica a formação para atuação com crianças de zero a cinco anos. De todo modo, a normativa representa o reconhecimento da EI integrada aos sistemas de ensino, requerendo profissionais qualificados para o exercício da docência com as crianças pequenas.

Outro tópico importante desta resolução é a defesa da valorização do magistério. O Art. 18 atribui aos sistemas de ensino, às redes e às instituições educativas "a responsabilidade pela garantia de políticas de valorização dos profissionais do magistério da educação básica, que devem ter assegurada sua formação, além de plano de carreira, de acordo com a legislação vigente" (Brasil, 2015, p.14). Nesse contexto, apresenta avanços e atendimento às lutas dos profissionais ao definir valorização como resultado da articulação entre formação (inicial e continuada) e condições de trabalho, com destaque para remuneração digna e planos de carreira (Côco, 2018).

O período de vigência da Resolução 02/2015, porém, não permite uma análise a respeito de suas contribuições à formação de professores, uma vez que as universidades estavam em processo de implementação e adequação de seus currículos quando a referida normativa foi revogada, em 2019. Ainda assim, experiências em diferentes instituições de ensino superior brasileiras indicam "importantes impactos nos projetos institucionais direcionadas a maior organicidade das políticas de formação, bem como, nos desdobramentos efetivos nos projetos pedagógicos de curso e, consequentemente, na identidade institucional" (Dourado e Tuttman, 2019).

Contrariando os posicionamentos em defesa da manutenção e do fortalecimento da Resolução 02/2015, a Portaria no 2.167 (Brasil, 2019a) definiu, em dezembro de 2019, as Diretrizes Curriculares Nacionais para a Formação Inicial de Professores para a Educação Básica e instituiu a Base Nacional Comum para a Formação Inicial de Professores da Educação Básica, ao homologar o Parecer CNE/CP no 22/2019 do Conselho Pleno do CNE, que revogou a Resolução 02/2015. Antes mesmo da publicação desta Portaria e da Resolução 02/2019, os movimentos sociais vinham denunciando que essas normativas representam o atrelamento da formação de professores à proposição da Base Nacional Comum Curricular, centrada em direitos de aprendizagem (reduzindo o direito à educação); desconsideram os acúmulos do pensamento educacional brasileiro; apresentam interesses privatistas na educação pública; possuem propostas reducionistas da formação; e esvaziam o reconhecimento e da valorização da atuação docente, dentre outras problematizações (ANPEd, 2019).

Dada a interlocução com os documentos aqui analisados, destacamos que as discussões implicadas com a regulamentação da formação de professores abarcam a EI, movendo debates sobre as concepções de formação, os requisitos para atuação e as compreensões sobre os processos de ensino. Esses, entre outros elementos, remetem ao papel da educação na sua articulação com os projetos de nação em disputa. Nos tensionamentos vinculados à qualidade da oferta educacional e à formação de professores, urge não desconsiderar as imposições de controle na atuação, as reconfigurações dos quadros funcionais e as formas de encaminhar o reconhecimento profissional. Nos limites desta análise, todavia, não é possível desenvolver em detalhes os vários elementos presentes nas normativas que compõem esses - não menos importantes - intervenientes. 
Ainda assim, cabe observar, no contexto da EI: 1) a ameaça das políticas de avaliação de larga escala já inseridas nas outras etapas da educação básica, que, com testes padronizados para os estudantes, buscam regular a atuação docente e a dinâmica das instituições (Vieira e Côco, 2019); 2) a reconfiguração dos quadros funcionais que repercute na presença de profissionais auxiliares ao trabalho dos professores, cindindo a indissociabilidade das ações de cuidado e de educação com as crianças pequenas (Almeida e Côco, 2018); 3) a profissionalidade docente que demanda fortalecer seu reconhecimento como meio de busca por avanços na educação (Côco, 2018).

Ainda que seja possível assinalar questionamentos a respeito das legislações analisadas, o destaque para a Resolução 02/2015 representa espaço de promoção de debate sobre a política educacional nacional, na medida em que se constitui memória recente de resistência contra a imposição de novas alterações sem abertura para debates e discussões. Representa também propósitos de buscar avanços que assegurem a FI em articulação com a FC e em associação a políticas de reconhecimento e valorização dos profissionais, no bojo do fortalecimento do direito à educação.

\section{Considerações finais}

Compreender o cenário das políticas públicas e seus impactos para a educação brasileira é primordial diante de medidas econômicas e sociais que esvaziam conquistas e avanços alcançados nas últimas décadas, especialmente, porque afetam os processos de discussão da educação nacional. Focalizando os campos da FI articulados à EI, assinalamos, na análise dos percursos da legislação brasileira, mudanças na oferta de escolarização que exigiram alterações nos processos de formação e atuação dos profissionais. Em meio a desafios relacionados aos processos de formação, de configuração das carreiras e de condições de trabalho, essa complexidade vem se apresentando na EI vinculada à luta por garantir o direito à educação para todas as crianças, no bojo das transformações nos processos de institucionalização da infância (Rayna e Brougère, 2000).

As mudanças no trabalho educativo com as crianças no cenário brasileiro, evidenciam novas exigências profissionais, dada a articulação da EI à educação básica, cuja consequência é a presença progressiva na legislação educacional. Assim, observa-se o fortalecimento do caráter educativo da EI com sua inserção nos sistemas de ensino (Brasil, 1996), algo que favorece a proposição de uma pedagogia própria para essa etapa educacional (Rocha, 1999). Com isso, a EI passa a ser entendida como um espaço que deve valorizar a brincadeira e o lúdico numa perspectiva interdisciplinar dos saberes, integrando as dimensões do cuidado e da educação (Cerisara, 2004). Em síntese, nas apropriações, tensões e mobilizações, apontamos que a configuração do trabalho com a educação infantil ecoa em requisitos formativos para atuação nesse campo.

No contexto das transformações que marcam as políticas públicas brasileiras relacionadas ao direito à educação, em especial, das crianças pequenas, buscamos com este artigo analisar as premissas estabelecidas em ordenamentos legais para a FI de professores para a docência na EI. Para isso, retomamos a trajetória do curso de Pedagogia no Brasil, os indicativos da Resolução 01/2006 para o curso de graduação em Pedagogia, as metas do PNE, as diretrizes da Resolução 02/2015 para a FI em nível superior e para a FC, assim como as tensões decorrentes da instituição de uma Base Nacional Comum para a formação. Essas análises se efetivaram no reconhecimento de um contexto de questionamentos, sobretudo das alterações dos propósitos educacionais e da redução dos 
investimentos, em meio aos desafios para avançar nas metas preconizadas para a educação, impactando a formação de professores.

Em razão dessas disputas, que envolvem interesses teóricos, políticos e econômicos, posicionamo-nos no debate sobre os quadros funcionais em defesa da valorização dos profissionais que vivificam o trabalho educativo com as crianças pequenas. Ao participarmos dessa cadeia dialógica, reiteramos a defesa da formação docente em nível superior, também para professores da EI, ainda que as normativas admitam a formação em nível médio na modalidade Normal. Indicamos também a importância de que a FI atente para uma pedagogia da infância que considere a especificidade da primeira etapa da educação básica, abrangendo a creche e a pré-escola.

As problematizações referentes à organização curricular dos processos de FI, à dinâmica das ações de FC e às interfaces com o campo de trabalho assinalam que os ordenamentos legais se efetivam em meio a disputas e tensões. Diante disso, a FI em nível superior se apresenta como conquista do campo da EI, na medida em que reconhece a defesa do direito das crianças pequenas à educação de qualidade. Esse reconhecimento não pode prescindir do cumprimento das metas e estratégias do PNE, portanto, de investimentos qualificados na formação de professores, de modo a garantir a ampla participação das categorias profissionais, dos movimentos e organizações sociais e da sociedade civil, que tem, na Constituição Federal, garantido o seu direito à educação.

Reconhecendo os diferentes posicionamentos que instam as discussões sobre a educação brasileira, advogamos a continuidade dos debates, uma vez que os dilemas enfrentados em torno da formação de professores, implicadas com a garantia do direito à educação, não se reduzem às normativas, ainda que não se apartem delas. Diante das aceleradas mudanças políticas e sociais, urge mantermos acesas as discussões, com vistas a indagar as perspectivas apresentadas aos desafios que marcam o contexto. Assim, finalizamos este texto reiterando o convite à continuidade das interlocuções acerca da FI para a docência na EI, na expectativa das contrapalavras que continuem a mover essa cadeia dialógica. Afirmando a democracia, buscamos as provocações que convidam ao debate aqueles que, responsivamente, se dispõem à defesa da educação pública, gratuita, laica, inclusiva e de qualidade socialmente referenciada para todos.

\section{Referências}

Almeida, G. M. e Côco, V. (2018). Trabalho docente na educação infantil: a participação das auxiliares de creche. Actualidades Pedagógicas, 72, 97-117. https://ciencia.lasalle.edu.co/ap/vol1/iss72/6/

Associação Nacional de Pós-Graduação e Pesquisa em Educação (ANPEd) (2019a). Posição da ANPEd sobre a questão da formação inicial e Continuada de Professores e seu marco legal Resolução CNE/CP no 2, de 1 de julho de 2015. http://www.anped.org.br/sites/default/files/images/cne_06maio_posicionamento_ anped.pdf

Associação Nacional de Pós-Graduação e Pesquisa em Educação (ANPEd) (2019b). Uma formação formatada. Posição da ANPEd sobre o "texto referência - diretrizes curriculares nacionais e base nacional comum para a formação inicial e continuada 
de professores da educação básica". https://anped.org.br/news/posicao-da-anpedsobre-texto-referencia-dcn-e-bncc-para-formacao-inicial-e-continuada-de

Associação Nacional de Pós-Graduação e Pesquisa em Educação (ANPEd) (2018). A proposta de BNCC do ensino médio: alguns pontos para 0 debate. http://www.anped.org.br/sites/default/files/images/anped_contra_bncc_em_para_ cne_maio_2018.pdf

Associação Nacional pela Formação dos Profissionais da Educação (2018). Manifesto ANFOPE em defesa da Formação de Professores. http://www.anped.org.br/news/manifestoanfope-em-defesa-da-formacao-de-professores

Associação Nacional de Pós-Graduação e Pesquisa em Educação (ANPEd) (2016). Editorial. Boletim ANPED, 5(20). Número especial "Conquistas em riscos". http://www.anped.org.br/boletim/23/2016/11

Associação Nacional de Pós-Graduação e Pesquisa em Educação (ANPEd) (2015). Exposição de Motivos sobre a Base Nacional Comum Curricular. Ofício n. ${ }^{\circ}$ 01/2015/GR. Rio de Janeiro,

RJ. http://www.anped.org.br/sites/default/files/resources/Of_cio_01_2015_CNE_BNC C.pdf

Associação Nacional pela Formação dos Profissionais da Educação (ANPEd) (2011). Documento Final do $15^{\circ}$ Encontro Nacional. Em Brzezinski, I. (Org). ANFOPE em movimento 2008-2010 (pp. 13-58). Líber Livro. Anfope. CAPES. Anexo I. http://www.gppege.org.br/

Bakhtin, M. M. (2011). Estética da criação verbal (6a ed.). Martins Fontes.

Bakhtin, M. M. (2010). O discurso no romance. In: M. Bakhtin. Questões de literatura e de estética: a teoria do romance (6a. ed.), 71-210. Hucitec.

Bakhtin, M. M. (2006). Marxismo e filosofia da linguagem (12a ed.). Hucitec.

Ball, S. J. (2001). Diretrizes políticas globais e relações políticas locais em educação. Currículo sem Fronteiras, 1(2), 99-116. http://www.curriculosemfronteiras.org/vol1iss2articles/ball.pdf

Ball, S. J. (2009). Entrevista com Stephen Joseph Ball: um diálogo sobre justiça social, pesquisa e política educacional. Entrevista concedida a Mainardes, J. e Marcondes, M. I. Educação e Sociedade, 30(106), 303-318. http://www.cedes.unicamp.br

Bloch, M. (2002). Apologia da História ou o Ofício do Historiador. Jorge Zahar Editor.

Brasil (1939). Decreto-Lei no 1.190, de 4 de abril de 1939. Dá organização à Faculdade Nacional de Filosofia. Brasília, DF. https://www2.camara.leg.br/legin/fed/declei/1930-1939/decreto-lei-1190-4-abril1939-349241-publicacaooriginal-1-pe.html

Brasil (1971). Lei n. 5.692, de 11 de agosto de 1971. Diretrizes e Bases para o ensino de 1.0 e 2.0 graus. Brasília, DF. https://www2.camara.leg.br/legin/fed/lei/19701979/lei-5692-11-agosto-1971-357752-publicacaooriginal-1-pl.html

Brasil (1988). Constituição da República Federativa do Brasil de 1988. Senado Federal. 
Brasil (1996). Lei n. 9.394, de 20 de dezembro de 1996. Diretrizes e bases da educação nacional. Brasília, DF. http://www.planalto.gov.br/ccivil_03/leis/19394.htm

Brasil (2006). Resolução CNE/CP n.o 1, de 15 de maio de 2006. Institui as Diretrizes Curriculares Nacionais para o Curso de Graduação em Pedagogia, licenciatura. Brasília, DF. http://portal.mec.gov.br/cne/arquivos/pdf/rcp01_06.pdf

Brasil (2006). Emenda Constitucional n. 53, de 19 de dezembro de 2006. Dá nova redação aos arts. 70, 23, 30, 206, 208, 211 e 212 da Constituição Federal e ao art. 60 do Ato das Disposições Constitucionais Transitórias. Brasília, DF. http://www.planalto.gov.br/ccivil_03/constituicao/Emendas/Emc/emc53.htm

Brasil (2009). Resolução CNE/CEB n.o 05, de 17 de dezembro de 2009. Fixa as diretrizes curriculares nacionais para a educação infantil. http://portal.mec.gov.br/dmdocuments/rceb005_09.pdf

Brasil (2014). Lei no 13.005, de 25 de junho de 2014. Aprova o Plano Nacional de Educação e dá outras providências. http://www.planalto.gov.br/ccivil_03/_ato20112014/2014/lei/l13005.htm

Brasil (2015). Resolução CNE/CP n. 02, de 10 de julho de 2015. Diretrizes Curriculares Nacionais para a formação inicial em nível superior e para a formação continuada. Brasília, DF. http://portal.mec.gov.br/docman/agosto-2017-pdf/70431-res-cne-cp002-03072015-pdf/file

Brasil (2019a). Portaria no 2.167, de 19 de dezembro de 2019. Diretrizes Curriculares Nacionais para a formação inicial de Professores para a Educação Básica e Base Nacional Comum para a formação inicial de Professores da Educação Básica - BNC Formação. Brasília, DF. http://portal.mec.gov.br/index.php?option=com_docman\&view=download\&alias= 133091-pcp022-19-3\&category_slug=dezembro-2019-pdf\&Itemid=30192

Brasil (2019b). Resolução CNE/CP n O 2, de 20 de dezembro de 2019. Diretrizes Curriculares Nacionais para a Formação Inicial de Professores para a Educação Básica Base Nacional Comum para a Formação Inicial de Professores da Educação Básica (BNCFormação). Brasília, DF. http://portal.mec.gov.br/docman/dezembro-2019pdf/135951-rcp002-19/file

Brasil (2019c). Parecer CNE/CP no: 22 de 7 de novembro de 2019. Revisa e atualiza a Resolução CNE/CP no 2, de $1^{0}$ de julho de 2015. http://portal.mec.gov.br/docman/dezembro-2019-pdf/135951-rcp002-19/file.

Buss-Simão, M. e Rocha, E. A. C. (2018). Docência na educação infantil: uma análise das redes municipais no contexto catarinense. Rev. Bras. Educ., 23, 1-20. http://www.scielo.br/scielo.php?script=sci_arttext\&pid=S141324782018000100216

Côco, V., Galdino, L. e Vieira, M. A. (2017). Trajetórias de formação: perspectivas para a docência na educação infantil. Revista Espaço do Currículo, 10(2), 272-289. https://periodicos.ufpb.br/index.php/rec/article/view/rec.v10i2.35502

Côco, V. (2013). Conquistas, avanços, desafios e disputas na política de educação infantil: Transformações na docência... Em nós. Em Rangel, I. S., Nunes, K. R. e Côco, V. 
(Orgs.) Educação infantil: redes de conversações e produções de sentidos com crianças e adultos. (pp. 181-199). Petrópolis, RJ: De Petrus.

Côco, V. (2018). Educação infantil: considerações sobre a formação de professores. Educação em Análise, 6-26. http://www.uel.br/revistas/uel/index.php/educanalise/article/view/33681

Côco, V., Vieira, M. N. e Giesen, K. F. (2018). Formação inicial para a docência na educação infantil: indicadores da produção acadêmica. Revista Faeeba, 27(51), 69-84. https://www.revistas.uneb.br/index.php/faeeba/article/view/4967

Côco, V., Vieira, M. N. e Giesen, K. F. (2019). Docência na educação infantil: desafios e perspectivas da formação inicial em pedagogia. Momento: diálogos em educação, 28(1), 417-435. https://periodicos.furg.br/momento/article/view/8056

Côco, V., Reis, M. L., Vieira, M. N., Lovatti, R. R. e Zucolotto, V. M. (2015). O Plano Nacional de Educação: desafios no campo da educação infantil. Eccos Revista Científica (Online), 37, 77-92. https://periodicos.uninove.br/index.php?journal=eccos\&page=article\&op=view\&pa th $\% 5 B \% 5 D=5553$

Conferência Nacional de Educação (2010). Documento - referência. Fórum Nacional de Educação. Brasília, DF: Ministério da Educação. http://conae.mec.gov.br/images/stories/pdf/pdf/documetos/documento_final_sl.p $\mathrm{df}$

Cunha, M. I. (2013). O tema da formação de professores: trajetórias e tendências do campo na pesquisa e na ação. Revista Educação e Pesquisa, 3, 609-625. http://scielo.br/pdf/ep/v39n3/aop1096.pdf

Dourado, L. F. (2015). Diretrizes curriculares nacionais para a formação inicial e continuada dos profissionais do magistério da educação básica: concepções e desafios. Educação $\quad$ \& $\quad$ Sociedade, 299-324. http://www.scielo.br/pdf/es/v36n131/1678-4626-es-36-131-00299.pdf

Dourado, L. F. e Tuttman, M. T. (2019). Formação do Magistério da Educação Básica nas universidades brasileiras: institucionalização e materialização da Resolução CNE CP no 2/2015. Formação em Movimento, 1(2), 197-217. http://costalima.ufrrj.br/index.php/FORMOV/issue/view/108/DA.

Durli, Z. (2007). O processo de construção das diretrizes curriculares nacionais para o curso de pedagogia: concepções em disputa. [Tese de doutorado, Universidade Federal de Santa Catarina]. Repositorio institucional UFSC. https://repositorio.ufsc.br/bitstream/handle/123456789/89732/247336.pdf?seque nce

Durli, Z. e Bazzo, V. L. (2008). Diretrizes Curriculares para o curso de Pedagogia: concepções em disputa. Atos de Pesquisa em Educação, 3(2), 201-226. https://proxy.furb.br/ojs/index.php/atosdepesquisa/article/view/938

Kramer, S. (2000). Linguagem, cultura e alteridade. Para ser possível uma educação depois de Auschwitz, é preciso educar contra a barbárie. Enrahonar, 31, 149159.https://grupoinfoc.com.br/publicacoes/periodicos/p48_Linguagem_cultura_e_ 
alteridade._Para_ser_possivel_uma_educacao_depois_de_Auschwitz_e_preciso_ed ucar_contra_a_barbarie.pdf

Kramer, S. (1995). A política do pré-escolar no Brasil: a arte do disfarce (5a ed.). Cortez.

Plaisance, E. (2004). Para uma sociologia da pequena infância. Educação e Sociedade, 25(86), 221-241. http://www.scielo.br/pdf/es/v25n86/v25n86a11.pdf

Quinteiro, J. e Carvalho, D. C. de (Org.). (2007). Participar, brincar e aprender: exercitando os direitos da criança na escola. Junqueira \& Marin; CAPES.

Rayna, S. e Brougère, G. (2000). Tendences et innovations dans l'éducation préscolaire: perspectives internationals. INPR.

Rocha, E. A. (1999). A pesquisa em educação infantil no Brasil: trajetória recente e perspectivas de consolidação de uma pedagogia. (Tese de doutorado, Faculdade de Educação.

Unicamp, Campinas). http://www.bibliotecadigital.unicamp.br/document/?code=vtls000184228

Saviani, D. (2007). Pedagogia: o espaço da educação na Universidade. Cadernos de Pesquisa, 37(130), 99-134. http://www.scielo.br/pdf/cp/v37n130/06.pdf

Saviani, D. (2009). Formação de professores: aspectos históricos e teóricos do problema no contexto brasileiro. Revista Brasileira de Educação, 14(40), 143-155. http://www.scielo.br/pdf/rbedu/v14n40/v14n40a12.pdf

Scheibe, L. (2007). Diretrizes Curriculares para o Curso de Pedagogia: Trajetória Longa e Inconclusa. Cadernos de Pesquisa, 30-50. https://www.scielo.br/pdf/cp/v37n130/04.pdf

Scheibe, L. e Durli, Z. (2011). Curso de Pedagogia no Brasil: Olhando o Passado, Compreendendo o Presente. Educação em Foco, 17, 79-110. http://revista.uemg.br/index.php/educacaoemfoco/article/view/104

Silva, C. S. (2003). Curso de Pedagogia no Brasil: história e identidade. Autores Associados.

Vieira, M. N. e Côco, V. (2019). Pesquisas da pós-graduação brasileira: diálogos com a avaliação institucional na educação infantil. Dialogia, 31, 91-100. https://periodicos.uninove.br/dialogia/article/view/11471 